Special Issue of the 6th International Congress \& Exhibition (APMAS2016), Maslak, Istanbul, Turkey, June 1-3, 2016

\title{
La-Based Material for Energy Storage Applications
}

\author{
F.E. Atalay*, H. Kaya, A. Bingol and D. Asma \\ Inonu University, Science and Art Faculty, Department of Physics, Malatya 44280, Turkey
}

\begin{abstract}
In this work, nanostructured La-based materials were produced by chemical precipitation method onto Cladosporium cladosporioides fungal hyphae in aqueous solution. Materials were annealed at various temperatures between $100^{\circ} \mathrm{C}-600^{\circ} \mathrm{C}$. The morphological properties of the synthesized material were studied by transmission electron microscopy. The surface area for sample annealed at $360^{\circ} \mathrm{C}$ was determined to be $85.64 \mathrm{~m}^{2} / \mathrm{g}$ using Brunauer-Emmett-Teller method. The nitrogen adsorption and desorption isotherm displayed a typical typeIV isotherm. Electrochemical properties of produced material were studied using cyclic voltammetry, long term charge/discharge analysis and impedance spectroscopy in the $0.5 \mathrm{M} \mathrm{Na}_{2} \mathrm{SO}_{4}$ electrolyte. The obtained nanostructured porous electrode exhibits quasi-rectangular shaped cyclic voltammetry curves with a specific capacitance of $2190 \mathrm{~F} / \mathrm{g}$ at a scan rate of $2 \mathrm{mV} / \mathrm{s}$.
\end{abstract}

DOI: 10.12693/APhysPolA.131.453

PACS/topics: 81.07.-b, 82.47.Uv

\section{Introduction}

Recently, rare earth metal oxide and hydroxide nanomaterials have been extensively investigated because these materials have many potential applications in electronics, optics, catalysis, magnetic data storage, hydrogen storage, automotive industry and biotechnology. Nanomaterials with different sizes and shapes have been synthesized with various methods, such as chemical precipitation, solvothermal, sol-gel and hydrothermal method. However, there are very few studies on preparation and characterization of La-based oxide nanomaterials.

Currently, supercapacitors are one of the most promising energy storage systems. So far, nanostructured metal oxide materials, such as $\mathrm{NiO}, \mathrm{RuO}_{2}, \mathrm{Co}_{3} \mathrm{O}_{4}$ and $\mathrm{Mn}_{x} \mathrm{O}_{y}$, have been used as a supercapacitor electrode active material. Lanthanum element with its special electron shell structure has obvious influence on the capabilities of many materials [1]. It is well known that La-based oxide nanomaterials have not been reported as electrode active materials.

The surface area of electrode active material is a very important parameter to affect supercapacitor performance. The surface area can be increased using a biotemplate. We have used outer surface of bacteria and fungi as a biotemplate in our earlier work [2-4]. It was reported that especially fungal cell walls can act as cation exchangers, because of their negative charge, which originates from the presence of different functional groups, e.g. carboxylic, phosphate, amine or sulfhydryl groups $[5,6]$. The tubular structure of fungi results in high tolerance towards metals, high wall-binding capacity and intracellular metal uptake capabilities, compared to bacterial strains [4].

In this work, for the first time nanostructured La-based metal oxide materials with high surface-to-volume ratio

*corresponding author; e-mail: funda.atalay@inonu.edu.tr are synthesized using fungus as biotemplate. We have examined their usage in energy storage application as an electrode active material.

\section{Materials and equipment}

We have used similar methods in our earlier work [4] to produce nanostructured La-based metal oxide. Approximately $50 \mathrm{ml}$ suspension of $\mathrm{C}$. cladosporioides fungus was used as a biotemplate. $500 \mathrm{ml}$ of $0.1 \mathrm{M} \mathrm{La}\left(\mathrm{NO}_{3}\right)_{2}$ solution was added to a cell suspension of C. cladosporioides at $10 \mathrm{ml} / \mathrm{min}$, using a Metrohm 807 dosing unit. After shaking the mixture for 30 minutes, $250 \mathrm{ml}$ of $0.1 \mathrm{M} \mathrm{NaBH}_{4}$ solution, used as a reducing agent, was added to the mixture at $10 \mathrm{ml} / \mathrm{min}$ using dosing unit. This mixture was shaken at $800 \mathrm{rpm}$ for 24 hours. Then, $\mathrm{La}(\mathrm{OH})_{3}$ /fungus precipitate was obtained by centrifugation at $9000 \mathrm{rpm}$ for $15 \mathrm{~min}$. The precipitate was washed twice with deionized water and once with ethanol, subsequently. The $\mathrm{La}(\mathrm{OH})_{3}$ /fungus precipitate was dried for 12 hours in a vacuum oven at $60^{\circ} \mathrm{C}$ at $600 \mathrm{mmHg}$ pressure. Then, the precipitate was annealed in air atmosphere for 12 hours at temperatures in range between $100^{\circ} \mathrm{C}$ and $600{ }^{\circ} \mathrm{C}$. Subsequently, the nanostructured La-based materials $(75 \%)$ and acetylene black $(20 \%)$ were grinded and mixed in a $\mathrm{Zr}_{2} \mathrm{O}_{3}$ mortar for $45 \mathrm{~min}$. Then PTFE (5\%) was added to mortar. The resultant mixture was grinded again for $60 \mathrm{~min} .5 \mathrm{mg}$ of the obtained homogeneous mixture was pressed on $\mathrm{Ni}$ foam under a pressure of $10 \mathrm{MPa}$ for $45 \mathrm{~min}$ and was used as the working electrode.

A reference electrode was composed of $\mathrm{Ag} / \mathrm{AgCl}$ (with ceramic frit, ALS, saturated $\mathrm{KCl}$, and $45 \mathrm{mV}$ versus SCE at $20^{\circ} \mathrm{C}$ ). Platinum was used in auxiliary electrodes. All of the electrochemical experiments were carried out in a three-electrode cell configuration in $0.5 \mathrm{M} \mathrm{Na}_{2} \mathrm{SO}_{4}$. Electrochemical investigations included cyclic voltammetry (CV) measurements, galvanostatic charge-discharge tests and electrochemical impedance spectroscopy (EIS) using a Gamry Reference 3000 potentiostat/galvanostat/ZRA. The electrochemical impedance spectroscopy (EIS) tests 
were conducted with a frequency loop from $100 \mathrm{kHz}$ to $10 \mathrm{MHz}$ with $5 \mathrm{mV}$ AC oscillation amplitude under an open-circuit potential.

The morphology of the La-based materials was characterized by scanning electron microscopy (SEM; JEOL JSM-7001F) and transmission electron microscopy (TEM; JEOL 2100F). Nitrogen adsorption was performed at $77.3 \mathrm{~K}$ by means of a Micromeritics Gemini VII 2390t. The surface area was calculated using the BET equation. The pore size distribution was determined by the Barrett-Joyner-Halenda (BJH) method.

Thermogravimetric analysis (TGA) curves and differential thermal analysis (DTA) curves were recorded using a Shimadzu TGA/DTA-50 systems, in air by heating samples from room temperature to $900{ }^{\circ} \mathrm{C}$ with a ramp rate of $10^{\circ} \mathrm{C} / \mathrm{min}$. The crystal structure and orientation were determined by a Rigaku Ultima-IV X-Ray Diffractometer (XRD) using $\mathrm{Cu} \mathrm{K}_{\alpha}$ radiation.

\section{Results and discussion}

The TG/DTA results of bare fungi and the La-based material on fungi, produced by chemical precipitation at temperatures in range $24^{\circ} \mathrm{C}-800^{\circ} \mathrm{C}$, are shown in Fig. 1a.
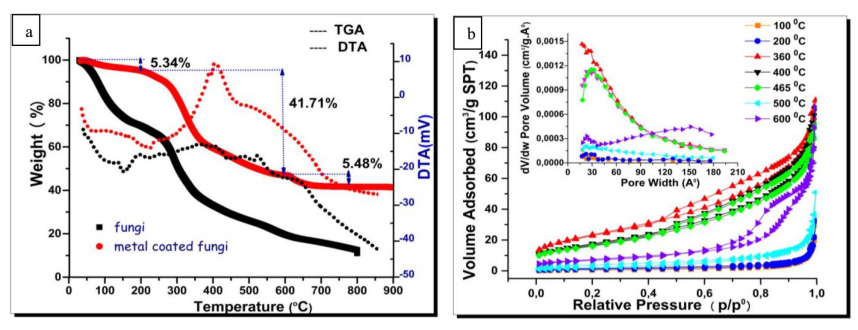

Fig. 1. (a) TGA/DTA measurements of bare fungi and La-coated fungi. (b) Nitrogen adsorption isotherm of nanostructured La-based material, annealed at various temperatures. Inset shows BJH pore size distribution of La-based material.

TGA/DTA measurements were made to determine transition temperatures of $\mathrm{La}(\mathrm{OH})_{3}$ to $\mathrm{LaOOH}$ and $\mathrm{La}_{2} \mathrm{O}_{3}$. The total weight loss at $800^{\circ} \mathrm{C}$ for bare fungi and metal coated fungi is $89.02 \%$ and $52.53 \%$, respectively. We have recently reported that the steady weight loss from room temperature to $120^{\circ} \mathrm{C}$ for bare fungi is due to initial loss of moisture. Subsequent steady weight loss from $120^{\circ} \mathrm{C}$ to $290^{\circ} \mathrm{C}$ can be attributed to the continual expulsion of water and ethanol from the sample. Final steady weight loss in the temperature range of $290^{\circ} \mathrm{C}-800^{\circ} \mathrm{C}$ can be attributed to fungal degradation [4]. It is seen from TGA curve for metal coated fungi that the weight loss has occurred at three steps. The first step of weight loss is $5.04 \%$ at $210^{\circ} \mathrm{C}$. It arises from $\mathrm{La}(\mathrm{OH})_{3}$ to $\mathrm{LaOOH}$ transformation and also from simultaneous degradation of the fungi. The next step of gradual weight loss up to $600{ }^{\circ} \mathrm{C}$ is of $41.71 \%$ and can be attributed to $\mathrm{LaOOH}$ to $\mathrm{La}_{2} \mathrm{O}_{3}$ transformation. The third step of weight loss up to $770^{\circ} \mathrm{C}$ is of $5.48 \%$. It is due to removal of nitrate ion from sample. The endothermic peaks on the DTA curve, appearing at $375^{\circ} \mathrm{C}$ and $500^{\circ} \mathrm{C}$, show the decomposition reaction of lanthanum compound. After heating to $375^{\circ} \mathrm{C}$, LaOOH has formed. The peak at approximately $500^{\circ} \mathrm{C}$, suppressed by the first peak, results from $\mathrm{La}_{2} \mathrm{O}_{3}$ formation.

The specific surface area is a significant microstructural parameter of materials, which depends on the geometrical shape and porosity. It is also well known that a large surface area could be an important factor, improving the electrochemical performance of supercapacitors. Yang et al. [7] have reported that the electrochemical performance can be improved by the hierarchical nanostructural design, integrating the high conductivity and large surface areas of the electrode, to permit homogeneous interface/chemical distributions at the nanoscale and fast ion and electron transfers. Figure $1 b$ shows the BET surface area measurement results for samples annealed in $100{ }^{\circ} \mathrm{C}-600^{\circ} \mathrm{C}$ temperature range. The samples annealed at $360^{\circ} \mathrm{C}, 400^{\circ} \mathrm{C}$ and $465^{\circ} \mathrm{C}$ exhibit specific surface area of $85.64,64.26$ and $59.80 \mathrm{~m}^{2} / \mathrm{g}$, respectively. The inset of Fig. 1b shows the BJH desorption pore size distribution curves of annealed samples. We can see that most of the micropores in all samples have a size smaller than $18 \mathrm{~nm}$. The most probable pore size, estimated from the peak position, is about $2.3 \mathrm{~nm}$ for the sample annealed at $360^{\circ} \mathrm{C}$. The mesapore structure collapsed above $465^{\circ} \mathrm{C}$ due to crystallization of $\mathrm{La}_{2} \mathrm{O}_{3}$, which results from decrease in surface area and increase in average pore with. The BET surface area of $600{ }^{\circ} \mathrm{C}$ annealed sample has reduced to $26.6 \mathrm{~m}^{2} / \mathrm{g}$.

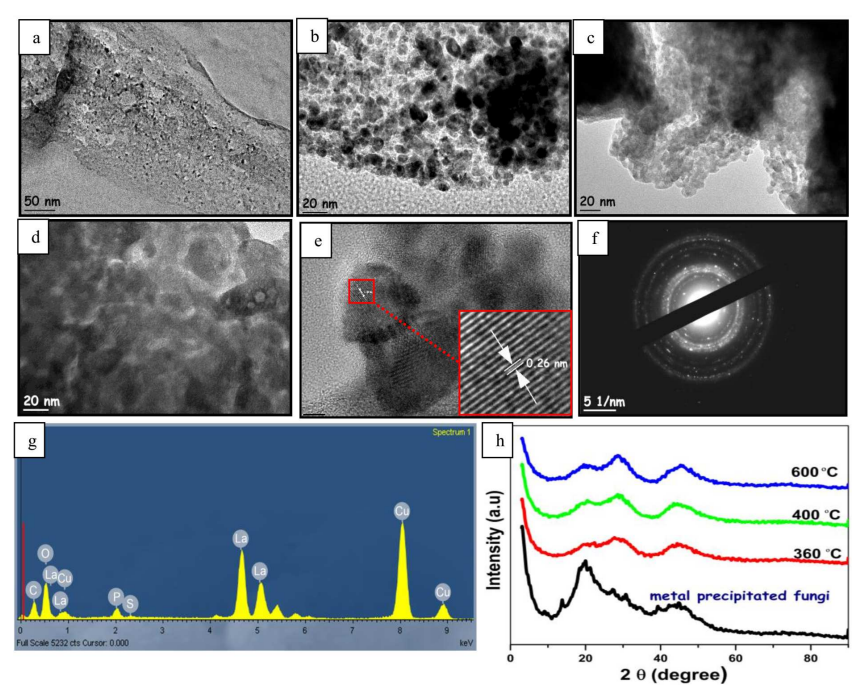

Fig. 2. TEM images of La-based materials, annealed at various temperatures. (a) $100^{\circ} \mathrm{C}$, (b) $360^{\circ} \mathrm{C}$, (c) $400{ }^{\circ} \mathrm{C}$, (d) $600^{\circ} \mathrm{C}$, (e) HRTEM image, (f) SAED pattern, (g) EDS pattern and (h) XRD pattern of the sample annealed at $360^{\circ} \mathrm{C}$.

Figure $2 \mathrm{a}-\mathrm{d}$ shows the size and morphology of Labased materials produced on fungi. It can be seen that the most nanoporous structure, among the annealed 
samples, has the sample annealed at $360^{\circ} \mathrm{C}$ (Fig. 2b). The high magnification TEM image of sample annealed at $360^{\circ} \mathrm{C}$ shown in Fig. 2e also indicates that the particles are all crystalline and their sizes again fall in the range of $6-20 \mathrm{~nm}$. The spacing between the fringes is about $2.6 \AA$. Figure $2 \mathrm{f}$ shows the corresponding selected area electron diffraction (SAED) pattern. The SAED pattern illustrates the fine grained polycrystalline structure of sample. Figure $2 \mathrm{~g}$ shows the energy dispersive analysis (EDS) pattern of the sample. The significant peaks around $4.66 \mathrm{keV}$ and $5.05 \mathrm{keV}$, show the presence of La. To confirm these findings, XRD studies were conducted as shown Fig. 2h. The broad XRD peaks are observed for all samples, which is an exhibition of formation of nanocrystals.

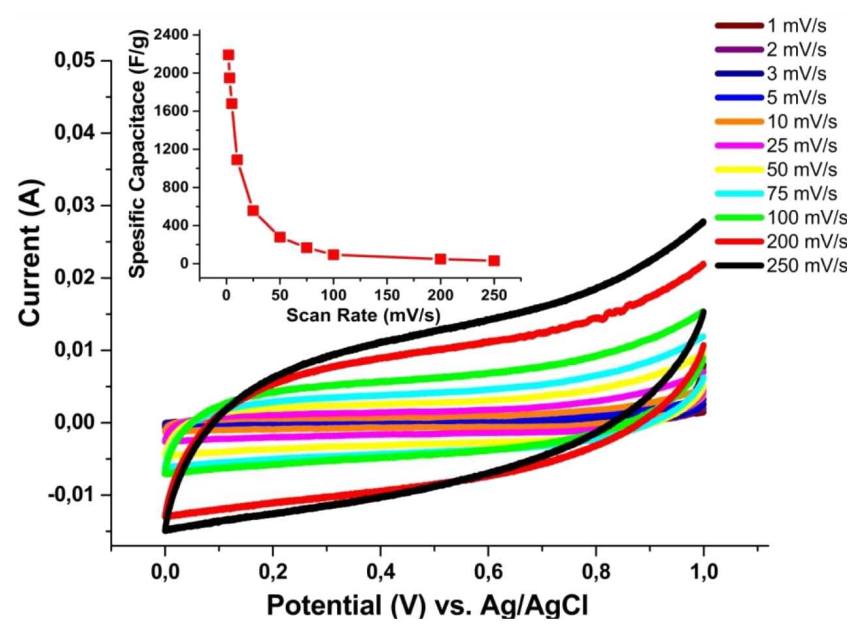

Fig. 3. CV curves of La-based electrodes at different scan rates. The inset shows the specific capacitance as a function of the scan rate.

A quasi-rectangular shape of $\mathrm{CV}$ curves shows that the La-based supercapacitor electrode has electrochemical capacitive performance over the potential window between $0 \mathrm{~V}$ and $1 \mathrm{~V}$, as shown in Fig. 3. Wand et al. [8] have reported that quasi-rectangular shape of $\mathrm{CV}$ arises from unique electrochemical features of electrode active materials, such as reversible redox process, high thermal and chemical stability and pseudo capacitance. The CV curves with same shape at all scan rates also indicate a good capacitive performance of electrode. The specific capacitance was calculated from the $\mathrm{CV}$ curves using the following equation:

$$
C_{\mathbf{s}}=\frac{\int I \mathrm{~d} V}{s \Delta V m},
$$

where $I$ is the current, $s$ is the scan rate, $\Delta V$ is the potential window and $m$ is the mass of the active material. La-based electrode yielded the maximum specific capacitance of $2190 \mathrm{~F} / \mathrm{g}$ at $2 \mathrm{mV} / \mathrm{s}$ (as shown in the inset of Fig. 3). When the scan rate is changed to $5 \mathrm{mV} / \mathrm{s}$, the specific capacitance of the porous electrode is $93 \mathrm{~F} / \mathrm{g}$. It was also observed that the specific capacitance value decreases with increasing scan rate, which is due to limited ion movement at high scan rates. Specific energy density and power density were also calculated from the the CV curves and are equal to $304.1 \mathrm{Wh} / \mathrm{kg}$ and $2190 \mathrm{~W} / \mathrm{kg}$, respectively.

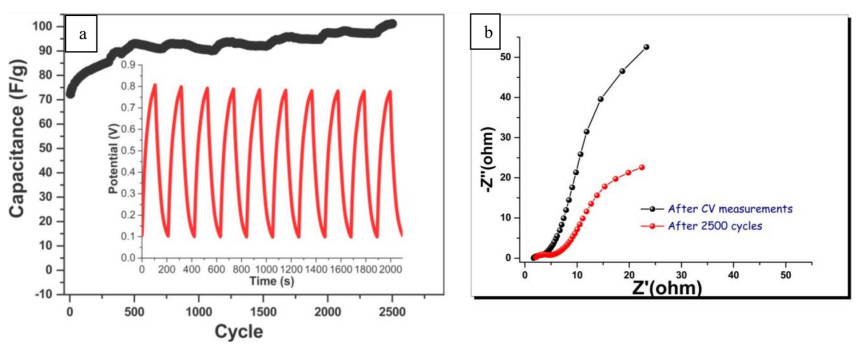

Fig. 4. (a) The variation of specific capacitance as a function of cycle number of La-based electrode. The inset shows the ten cyclic charge-discharge curves. (b) Nyquist plots of La-based electrode at open circuit potential in $1 \mathrm{M} \mathrm{Na}_{2} \mathrm{SO}_{4}$ electrolyte.

The first ten galvanostatic charge-discharge cycles of nanostructured La-based electrode at current of $0.4 \mathrm{~A} / \mathrm{g}$ are given in the inset of Fig. 4a. The long term galvanostatic cyclability of the material was investigated over 2500 cycles. The initial capacitance value was $72 \mathrm{~F} / \mathrm{g}$. The capacitance value of porous electrode was increasing gradually during the cycling process. After 2500 continuous charge/discharge cycles, it has reached the maximum capacitance value of $102 \mathrm{~F} / \mathrm{g}$. This value is in a good agreement with the value obtained from $\mathrm{CV}$ curve at scan rate of $5 \mathrm{mV} / \mathrm{s}$. It was also seen that there is no capacitance loss with the increasing number of cycles. This improvement in capacitance of the electrode is the result of the gradual access of electrolyte ions to the active sites of the electrode surface with the continuous cycles $[9,10]$. The electrochemical behavior of nanostructured porous electrode was also investigated by EIS. Figure $4 \mathrm{~b}$ shows the Nyquist plots of symmetric cell after the CV measurements and long-term cycling at an open circuit potential. The visible semicircle in high frequency region is related to the charge transfer resistance $R_{\mathrm{ct}}$, which contributes to the pseudocapacitance. The contact resistance between the electrolyte and the electrode material is approximately 1.67 and $2.11 \Omega$, before and after the cycle test, respectively, which shows changes by $20 \%$. The estimated $R_{\mathrm{ct}}$ value is approximately $3.84 \Omega$. The sloped line in the low frequency range is associated with the ion diffusion within the electrode surface. After 2500 continuous cycles, an increase of charge transfer resistance in the middle frequency range is observed. The slope of the straight line in the low frequency range has decreased from $70^{\circ}$ to $49^{\circ}$.

\section{Conclusions}

In summary, La-based materials were synthesized with chemical precipitation method onto Cladosporium cladosporioides fungal hyphae. It has been found that the synthesized porous electrode, annealed at $360^{\circ} \mathrm{C}$, exhibits high surface area, high capacitance, long cycle life 
and good coulombic efficiency. The results obtained from the electrochemical studies suggest that La-based porous materials could be used as high performance materials for energy storage systems.

\section{Acknowledgments}

This work was supported by TUBITAK under project number MAG-113M335 and by Inonu University with the project number I.U.A.F-2016/24.

\section{References}

[1] G. Shao, Y. Yao, S. Zhang, P. He, Rare Metals 28 $132(2009)$.

[2] F.E. Atalay, D. Asma, H. Kaya, E. Ozbey, Mater. Sci. Semicon. Process. 38, 314 (2015).

[3] F.E. Atalay, H. Kaya, D. Asma, A. Bingol, Biointerface Res. Appl. Chem. 6, 1099 (2016).
[4] F.E. Atalay, D. Asma, H. Kaya, A. Bingoland, P. Yaya, Nanomater. Nanotechnol. 28, 6 (2016).

[5] M. Fomina, J. Charnock, A.D. Bowen, G.M. Gadd, Environ. Microbiol. 9, 308 (2007).

[6] Y.S. Chan, M.M. Don, Int. Arab. J. Antimicrob. Agents. 2, 1 (2012).

[7] Q. Yang, Z. Lu, J. Liu, X. Lei, Z. Chang, L. Luo, X. Sun, Prog. Nat. Sci.: Mater. Int. 23, 351 (2013).

[8] Y. Wang, J. Guo, T. Wang, J. Shao, D. Wang, Y.W. Yang, Nanomaterials 5, 1667 (2015).

[9] J. Candler, T. Elmore, B.K. Gupta, L. Dong, S. Palchoudhury, R.K. Gupta, New J. Chem. 39, 6108 (2015).

[10] Y.F. Yuan, X.H. Xia, J.B. Wu, X.H. Huang, Y.B. Pei, J.L. Yang, S.Y. Guo, Electrochem. Commun. 13, 1123 (2011) 